cene. The book became indispensable to a wide range of students interested in the Pleistocene, so that a second and expanded edition is welcome.

When one compares the two editions the first half on techniques turns out to have increased from 265 only to about 270 pages; but the second half (comprising Parts $\mathrm{V}$ and VI, the examples) has been extensively altered and rewritten: it has increased from just over 200 pages to just under 350 . The new edition is not as well produced as the old one. The reproduction of some line diagrams is distinctly dirty, and has deteriorated between editions as can be seen from a comparison of the fortynine diagrams included in the first half of the book. The heaviness of the type is somewhat variable even on a single page. In fact the original edition looks a better book.

Yet one is again filled with admiration for the tremendous range of Professor Butzer's knowledge. The book is heavily documented, seventy-five pages of references for 600 pages of text. The field of knowledge covered is full of uncertainties and personal hunches and at times the compressed, heavily documented style gives a much greater air of certainty than is in fact justified. Yet in other places the author's scepticism is profound; for example, the beginning of chapter 20 . I myself would have preferred a somewhat more leisurely treatment of a smaller field (possibly fewer examples) to give a non-expert more discussion of the value of the various types of evidence. This would probably have meant a more tentative and descriptive and perhaps less erudite approach that might well not have been what the author had in mind.

I am happy to report that although the "geography" of the original subtitle has now become "ecology" this merely reflects a fashion in words and not a radical change of subject.

B. W. Sparks

\section{African Butterflies}

Life Histories of South African Lycaenid Butterflies. By G. C. Clark and C. G. C. Dickson. Pp. xvi $+272+$ 108 plates. (Purnell: Cape Town, Johannesburg, London and New York, May 1972.) $£ 9$.

SPECIFIC identification of adults in a group of more than 148,000 species presents frequent difficulties. Identification of the immature stages of Lepidoptera is at present impossible for most species: relatively few have been reared, illustrated or preserved in collections. This handsome book goes a small part of the way towards filling this large gap in our knowledge.

The authors illustrate, mostly for the first time, the early stages of 125 of the 200 or so South African Lycaenidae. The eggs and each larval instar are figured, together with the pupa and adult butterfly. The colour-plates, which are based on the superb paintings of Clark, are generally good, although a harder paper would have improved the definition. The numbers accompanying each group of figures correspond to the species-number in the text, but are not invariably consecutive: for example, 106 and 107 appear after the plate of species Nos. 105 and 108. Concise information is given about larval feeding habits, external characters of the eggs, larvae and pupae, parasites of the early stages, flight period and behaviour of the adult, and species distribution in South Africa and (briefly) elsewhere. Many of these data are the result of extensive fieldwork by the authors, who were the first to trace the complicated life-histories of several species, a number of which are attended by ants or spend the whole or part of their larval existence in ants' nests where they are probably predaceous on ant larvae. One species has been reared on Psyllidae (Homoptera); others feed on Coccidae (Homoptera) during the early instars.

A key to the larvae would have made a useful addition to this book-even if only to genera-as would a note in the introduction drawing the attention of readers (abstracters in particular) to the description of a new species on page 7 , and to the several changes in nomenclature, many in disagreement with Stempffer (Bull. Br. Mus. Nat. Hist. (Ent.), Suppl. 10 ; 1967): for example, Argiolaus is elevated to generic status and zeuxo is transferred to Poecilmitis.

The authors conclude their introduction with the hope that others will be stimulated to continue their investigations into the life-histories of Lycaenidae: their book is not only stimulating in this respect but indispensable. The ecology and physiology of Lycaenid larva and ant association offer fascinating fields of study. Possible selective advantages enjoyed by ant-nest inhabiting larvae, perhaps by reduction from predator attack or protection from fire, could be worth investigation.

A. WATSON

\section{Sedimentology}

Carbonate Sediments and Their Diagenesis. By R. G. C. Bathurst. Pp. xix +620. (Elsevier: Amsterdam, London and New York, 1971.) Dfl. 90; $\$ 25.75$.
THIS book is concerned with modern carbonate sediments and the processes which they undergo following deposition. The first half of the book deals with carbonate particles that form in modern environments, especially skeletal fragments derived from the disintegration of the shells of organisms, and oöids, pisolites, peloids, and aragonite needles which compose lime-mud. The environments in which these particles form, mostly tropical shallow seas, including the Bahamas, the shelf of southern Florida, the Gulf of Batabana (Cuba), the Persian Gulf, and the shelf of British Honduras, serve as models to illustrate the interaction of the many parameters that are responsible for the formation of carbonate particles.

The second half of the book concerns itself with the subject of diagenesis, a term which applies to post-depositional alteration which particles undergo. This subject relates by and large to processes by which particles become cemented together to form rock. Cementation or "lithification" is one of the most important natural processes occurring at or near the surface of the Earth. Hence how carbonate particles cement together to form carbonate rock or limestone is an important concern of this book. The process of cementation also has economic implications. Porous limestones serve as reservoirs for oil, gas, and water; thus the degree of cementation and the reasons for elimination of pore space or the creation of secondary pores become important as principles of economic geology.

Although this book has been devoted to Bruno Sander of Austria, an inspiring pioneer in the study of carbonate fabric, much of the material presented is based on the work of geologists working in major oil companies. During the 1950s and early 1960s research in carbonate sediments advanced rapidly under the economic incentive of the needs to explore for oil and gas in limestones. Hence the major oil companies formed research groups in carbonate sedimentology and finally made available to the profession through the medium of publication the results of this fundamental research.

The book consists of thirteen chapters, a glossary of sedimentological terms not defined in the text, a reference section, and the index. It is an outstanding and stimulating synthesis of the field of carbonate sedimentology. It has been written for the graduate student. After digesting the contents of this book a student will be well versed and up to date in this field, even if he has no prior knowledge of carbonate sedimentology. The illustrations are excellent. It is the most outstanding volume of Elsevier's series "Developments in Sedimentology".

Gerald M. Friedman 